\title{
Using SDI and Web-Based System to Facilitate Disaster Management
}

\author{
A. Mansourian', A. Rajabifard ${ }^{2}$, M. J. Valadan Zoej ${ }^{3}$, I. Williamson $^{4}$ \\ ${ }^{1}$ mansourian@kntu.ac.ir, ${ }^{2}$ abbas.r@unimelb.edu.au, ${ }^{3}$ valadanzouj@kntu.ac.ir, ${ }^{4}$ ianpw@unimelb.edu.au \\ ${ }^{1,3}$ : Faculty of Geodesy \& Geomatics Eng., K.N.Toosi University of Technology \\ ${ }^{2,4}$ : Center for Spatial Data Infrastructure and Land Administration, Department of Geomatics, \\ The University of Melbourne
}

\begin{abstract}
Spatial data and related technologies have proven to be crucial for effective collaborative decisionmaking in disaster management. However, there are currently substantial problems with availability, access and usage of reliable, up-to-date and accurate data for disaster management. This is a very important aspect to disaster response as timely, up-to-date and accurate spatial data describing the current situation is paramount to successfully responding to an emergency. This includes information about available resources, access to roads and damaged areas, required resources, and required disaster response operations that should be available and accessible for use in a short period of time. Any problem or delay in data collection, access, usage and dissemination has negative impacts on the quality of decision-making and hence the quality of disaster response. Therefore, it is necessary to utilize appropriate frameworks and technologies to resolve current spatial data problems for disaster management.
\end{abstract}

This paper aims to address the role of Spatial Data Infrastructure (SDI) as a framework for the development of a web-based system as a tool for facilitating disaster management by resolving current problems with spatial data. It is argued that the design and implementation of an SDI model and consideration of SDI development factors and issues, together with development of a webbased GIS, can assist disaster management agencies to improve the quality of their decision-making and increase efficiency and effectiveness in all levels of disaster management activities.

The paper is based on an ongoing research project on the development of an SDI conceptual model and a prototype web-based system which can facilitate sharing, access and usage of spatial data in disaster management, particularly disaster response.

Keywords: Spatial Data, SDI, Web-based System, Disaster Management, Decision-Making 


\section{1- INTRODUCTION}

A disaster is defined as a serious disruption of the functioning of a community or a society causing widespread human, material, economic or environmental losses that exceed the ability of the affected community or society to cope using its own resources (ISDR, 2003). Based on the origin of their hazards, disasters can be classified into three main groups as natural disasters, technological disasters and man-made disasters. Earthquakes, flood, land slides, wind storms, drought, and wild fires are some examples of natural disasters; industrial accidents, transport (car, airborne, train ...) accidents and bomb explosions are some examples of technological disasters; and terrorist activities can be considered man-made disasters which may occur in the form of natural or technological accidents.

Disasters interrupt society by claiming lives, creating victims and destroying infrastructures and houses. When a disaster occurs, funds and budgets that have been assigned for development purposes are diverted to respond to that disaster and returning quality of life to normal. Disasters also have negative impacts on the environment as they affect natural resources. Therefore, considering society, economy and environment as the three main components of sustainable development, disasters have a negative impact on sustainable development which making appropriate management of disaster a necessity.

With this in mind, disaster management is defined as a cycle of activities including mitigation, preparedness, response and recovery. Mitigation efforts refer to those activities which reduce the vulnerability of society to the impacts of disasters. Preparedness efforts refer to those activities which make the government and disaster responders prepare for responding to a disaster, if it occurs. Response refers to the activities necessary to address the immediate and short-term effects of a disaster, which focus primarily on the actions necessary to save lives, to protect property, and to meet basic human needs. Relief, rescue, search, firefighting, medical service, permit control, sheltering, evacuation, law enforcement and many others are samples of disaster response activities. Recovery efforts refer to those activities that bring communities back to normal (such as reconstruction) and they should be toward meeting mitigation and preparedness needs. 
The experiences of disaster management activities, particularly responding to the attacks on the World Trade Center and the Pentagon on September 11, 2001 in USA have proven that spatial data can considerably facilitate disaster management as most of the required information for disaster management has a spatial component (Donohue, 2002 and Bruzewicz, 2003). In this respect, spatial data and related technologies such as Geographical Information System (GIS), Global Positioning System (GPS), remote sensing, and photogrammetry including visible, thermal and LIght Detecting And Ranging (LIDAR) imaging have proven crucial for effective disaster management. In fact without spatial data, one can not expect effective and efficient disaster management (Amdahl, 2002 and Cutter et. al, 2003). However, current studies show that although spatial data can facilitate disaster management, there are substantial problems with collection, access, dissemination and usage of required spatial data for disaster management (SNDR, 2002 and Jain and McLean, 2003). Such problems become more serious in the disaster response phase, with its dynamic and timesensitive nature.

Disaster response is dynamic and decision-makers need to be updated on the latest emergency situation. Disaster response is also time-sensitive with little allowance on delay in decision-making and response operations. Therefore, any problem or delay in data collection, access, usage and dissemination has negative impacts on the quality of decision-making and hence the quality of disaster response. With this in mind, it is necessary to utilize appropriate frameworks and technologies to resolve current spatial data problems for disaster management.

It is suggested that Spatial Data Infrastructure (SDI) as an initiative in spatial data management, along with appropriate web-based tools, can be used as an integrated framework for resolving current problems with spatial data. Such a tool can significantly contribute to the facilitation of sustainable development objectives. This paper aims to describe the development of an SDI conceptual model and a prototype web-based system that facilitates spatial data collection, access, dissemination, management and usage for proper disaster management. This is based on an ongoing research and case study in Iran which investigates the role of SDI and web-based GIS in disaster management with emphasis on the response phase. The research also draws on experience of other 
countries in utilizing spatial data for disaster management (particularly Australia and its GeoInsight project: GeoInsight, 2002).

\section{2- DISASTER MANAGEMENT COMMUNITY}

Different organizations (such as Fire, Medical and police departments; Red Cross Society; and Utility Companies) collaborate in disaster management due to the diversity of activities during a disaster, particularly in the response phase. Inter-organizational coordination of disaster response operations and controlling the emergency situation is generally conducted through an Emergency Operation Center (EOC) where the representatives of involved organizations are gathered. To achieve coordination, each of the representatives in the EOC is in touch with its own organization in order to update itself and other EOC members about emergency situations.

As mentioned earlier, decision-makers in involved organizations and the EOC together with emergency workers need reliable and up-to-date spatial data for proper disaster response. Road networks, buildings, hospitals, fire stations, medical emergency stations, utility networks, damaged areas, closed roads, permit controls, burning areas, and damaged facilities and their associated attribute data are some examples of required datasets for disaster response. Some of these datasets need to be collected and kept up-to-date before the occurrence of a disaster (such as topographic maps, urban base maps and utility network maps) and some parts of datasets need to be regularly collected and updated after the occurrence of a disaster in aftermath of emergency situations (such as damaged areas, closed roads and burning areas).

However, because of the variety of required datasets for disaster response, no individual organization can collect and keep up-to-date all of its required spatial datasets before and particularly after occurrence of disasters. Also, just one organization (being assigned as responsible for data collection) cannot collect and update all of the required datasets for all involved organizations. Therefore, collecting and updating datasets for disaster response should be done jointly, through a collaborative effort and partnership of organizations in spatial data collection/production and sharing. 


\section{3- A MODEL FOR SPATIAL DATA SHARING}

Organizations involved in disaster management community are the main stakeholders for producing, updating and maintaining required spatial datasets for disaster response. If each of the involved organizations collects some part of the required spatial datasets for disaster response (relevant to its tasks) during everyday business and disaster response, required spatial datasets can always be available to decision-makers. If this data is shared and exchanged, then datasets are accessible to the wider disaster management community. This collaborative environment is based on the concept of partnerships in spatial data production and sharing.

Although a partnership model for spatial data collection and sharing can resolve the problem with collection, access and dissemination of required spatial data for disaster response, relevant research into collaborative efforts in spatial data production, sharing, and exchange shows that there are different technical (such as standards and interoperability models) and non-technical (such as social, cultural, and institutional) issues that create barriers for such participation (Nedovic-Budic and Pinto, 1999; McDougall et al., 2002 and Rajabifard and Williamson, 2003). Therefore, by creating an environment in which such issues are taken into consideration and resolved, facilitating spatial data access for decision-makers and emergency workers, the concept of partnership in data production, sharing and exchange can become a reality. In this way, Spatial Data Infrastructure (SDI, as an initiative in spatial data management) with related concepts and models, can be used as a framework for creating such an environment and consequently, facilitating disaster management.

\section{4- ROLE OF SDI IN DISASTER MANAGEMENT}

The growing need to organize data across different disciplines and organizations and also the need to create multi-participant, decision-supported environments has resulted in the concept of Spatial Data Infrastructure (SDI). SDI is an initiative intended to create an environment that will enable a wide variety of users to access, retrieve and disseminate spatial data in an easy and secure way. In principle, SDIs allow the sharing of data, which is extremely useful, as it enables users to save resources, time and effort when trying to acquire new datasets by avoiding duplication of expenses 
associated with generation and maintenance of data and their integration with other datasets. SDI is also an integrated, multi-leveled hierarchy of interconnected SDIs based on collaboration and partnerships among different stakeholders.

As illustrated in Fig. 1, an SDI encompasses the policies, access networks and data handling facilities (based on the available technologies), standards, and human resources necessary for the effective collection, management, access, delivery and utilization of spatial data for a specific jurisdiction or community.

\section{Fig. 1}

Viewing the core components of SDI, different categories of components can be formed based on the different nature of their interactions within the SDI framework (Rajabifard et al., 2002). Considering the important and fundamental role between people and data as one category, a second category can be considered to consist of the main technological components: the access networks, policy and standards. The nature of these two categories is very dynamic due to the changes occurring in communities (people) and their needs, as well as their ongoing requirement for different sets of data. Additionally, with the rapid development of technology, the need for the mediation of rights, restrictions and responsibilities between people and data are also constantly subject to change. According to this view, anyone (data users through to producers) wishing to access datasets must utilize the technological components.

With this in mind, due to the need for collaboration in spatial data production and sharing for disaster management, an SDI can be used as an appropriate framework to facilitate disaster management (particularly disaster response). This is due to the fact that SDI can define the relationship between people and data (Fig. 1) and can create an environment in which people can access, retrieve, and disseminate data, based on SDI's core component and relevant models. 
By clarifying each of these core components of SDI, an SDI conceptual model can be developed which can contribute to facilitating the availability, access and usage of spatial data for disaster management and hence facilitation of disaster management.

Considering Geographical Information System (GIS) as the underpinning technology for SDI and its role in facilitating data collection and storage as well as facilitating decision-making based on spatial data processing and analysis, GIS is a an appropriate tool for facilitating decision-making for disaster management. In this respect, a web-based GIS can be a good tool for facilitating disaster management due to the need for interaction between decision-makers in the disaster management community, particularly during disaster response.

Therefore, using SDI as a framework and a web-based GIS as a tool, disaster management can be facilitated by providing a better way of spatial data collection, access, management and usage.

\section{5- PILOT PROJECT: A CASE STUDY}

As part of the research, a pilot project has been designed and conducted in Iran to investigate the role of SDI and web-based GIS in disaster management, with emphasize on the response phase. Iran is a disaster prone country and very vulnerable to different natural disasters including earthquakes, floods, drought, landslides, desertification, deforestation and storms. The recent Bam (2003) earthquake which claimed more than 40,000 lives, injured over 30,000 people, severely damaged more than $80 \%$ of the city and totally destroyed the social infrastructure (IRSC, 2004) is just one of many examples that describe the vulnerability of Iran especially in urban and rural areas to disasters, particularly earthquakes. Tehran, the capital of Iran, is a megalopolis of about 8 million inhabitants, which a sever earthquake is presumed for. Studies show a strong earthquake caused by activity of the Ray Fault (one of the faults which pass through Tehran) will bring the largest damage in history to Tehran, including huge damage to buildings, urban facilities and human casualty (JICA and CEST, 2000). It is another example that shows Iran's vulnerability to disasters.

During the last decade, the Ministry of Interior (MOI) has been appointed to be responsible for disaster management in Iran, with the cooperation of different governmental, non-governmental and 
military organizations, particularly in terms of reducing disasters and their impacts. Although considerable effort has been undertaken, many activities still remain to be done in terms of effective and efficient use of new technologies, tools, innovations, and concepts to improve disaster management services in Iran.

Spatial data and related technologies can considerably improve disaster management; however initial studies show that they are not yet effectively and efficiently used in disaster management, particularly for disaster response, in Iran. Such inconsideration causes response to disasters particularly large ones- being followed by poor decision-making, control, and coordination and consequently inappropriate use of resources, inappropriate distribution of response units and long response times.

In this respect and based on what has been descried earlier, current research is being conducted to investigate the role of SDI and web-based GIS in disaster management, with emphasize on the response phase. Two important outputs through this research are:

- an SDI conceptual model as a framework to facilitate the development of an infrastructure for disaster management; and

- a Web-based system as a tool for data sharing, data exchange and data analysis using an SDI conceptual model.

The first output is to create an environment in which spatial data can be more available and accessible and used more appropriately to facilitate decision-making and the second output is to create relevant software and tools for accessing and analyzing data.

As described before, developing SDI for disaster management requires different technical and nontechnical factors to be met, which creates a multidisciplinary environment for research. In this regard, a six step case study approach has been taken for this research.

Research began with a literature review on theories relevant to the research with emphasis on disaster management, SDI, GIS, Information Communication Technology (ICT), and organizational behavior. With this background the research continued through an assessment of the disaster 
management community of Iran and relevant organizations with respect to spatial data from an SDI perspective. In this assessment, based on current SDI models, factors that influence spatial data sharing, and factors that influence participation of organizations in SDI development (Kevaney, 1995; McDougall et al., 2002; and Rajabifard and Williamson, 2003), the disaster management community of Iran was evaluated.

As a result of the assessment, an initial conceptual model for SDI was developed. The conceptual model included establishing a data framework; developing standards for data collection, storing, and sharing; developing access network specifications; policy considerations; and identifying responsible organizations for data collection and updating before and in the aftermath of emergencies. This was followed by establishing required guidelines for data collection and updating based on standards.

According to the results of the assessment and initial SDI conceptual model, a prototype web-based system with GIS functionalities was developed as a tool for data updating, sharing, and analysis and consequently facilitation of the decision-making process based on the SDI concept.

Based on the initial SDI conceptual model and developed prototype system, a pilot project with cooperation from twelve organizations in the disaster management community was conducted to respond to an assumed earthquake disaster. The main aims of conducting the pilot project were:

- to demonstrate the application and advantages of spatial data and related technologies for disaster management and consequently increasing the awareness of the disaster management community in this respect. Such awareness would help the research project and proposed models being supported by the disaster management community;

- to demonstrate the advantages of SDI for to the disaster management community and get their support to commit to long term development of SDI; and

- to use the feedback of the pilot project for qualifying the developed SDI conceptual model and design and development of the prototype web-based system. 
In this pilot, a maneuver scenario was defined with which involved organizations could experience a coordinated disaster response based on spatial data sharing and analysis. Prior to conducting the maneuver, required spatial datasets were collected from different organizations. They were prepared based on developed standards and integrated with the system. Also, training about the system and its usage, and individual responsibilities on collecting and updating datasets was carried out. During the maneuver, each organization updated its own spatial datasets within responding operations, and shared them with the disaster management community. Therefore each organization had access to its required spatial datasets to integrate and analyze those, using GIS functionalities to support its own decision-making for disaster response. With this in mind, it was found, such a web-based system that utilizes SDI can help in reducing the response lasting time, at least to $1 / 3$ of current situations, by having all information available and accessible for decision-makers, and conducting appropriate planning prior to any response operation. EOC had also access to all required information describing the current situation and hence has better control and coordination of disaster response activities.

Based on the results of the pilot project and the initial SDI conceptual model, better understanding on the status of disaster management community from technical and non-technical perspectives (that affect participation of organizations in SDI initiative) was gained. As a result of that, the initial SDI conceptual model together with the prototype web-based system were updated and was found to be an appropriate framework for disaster management.

The organizational assessment, SDI conceptual model and prototype web-based system are described below. It is mentionable that feedback of the results of the pilot project will be used for design and development of a functioning system according to the prototype system. Because of the dynamic nature of SDI, different maneuvers are going to be conducted using the SDI conceptual model and proposed system, to qualify the developed SDI conceptual model.

\section{6- ORGANIZATIONAL ASSESSMENT}

The Basic organizational behavior model (Robbins et. al, 1994) was recognized as an appropriate framework and was utilized for organizational assessment. 
According to basic organizational behavior model, the disaster management community consists of three tiers including individual (people), group (involved organizations in disaster management) and organizational system (disaster management community). Assessment was conducted at all three levels with respect to technical and non-technical variables that affect an organization at each level (Fig. 2). Fig. 2, shows the basic organizational behavior model (the triangle with three tires) and selected variables for assessment at each level.

\section{Fig. 2}

The results of organizational assessment show that the disaster management community of Iran does not have a clear regime for partnerships in data production and sharing. In this respect development of SDI for disaster response in Iran is a matter of social, technical and technological, political, institutional and economical challenges.

There are various social challenges that were identified as aspects that need to be emphasized in order to facilitate the SDI initiative. The first is the need to increase peoples awareness on the value of utilization of spatial data and related technologies for a disaster management community at policy, management and operational level (based on organizational pyramid model: Petch and Reeve, 1999). Other challenges include skill formation (working with and interpreting GIS and GPS data) and cultural issues in the use and sharing of spatial data. Increasing the awareness is a key factor in developing SDI for disaster response as it affects other factors in any three levels of disaster management community (people as individual level, involved organizations as group level, and disaster management community as organizational level).

Having a clear strategic plan with respect to disaster management and spatial data is essential but currently neither exists at the group level nor at the organizational level of the disaster management community. Also, clear regulations and policies are required at both group and organizational level to clarify the custodianship of datasets, access policies, and dissemination policies in the context of 
copyright and privacy rules as well as security considerations. In addition, policies are required with respect to inclusion of private and academic sector and appropriate use of their capabilities in terms of spatial data. These are also other challenges that should be considered in the context of social challenges.

With respect to technical and technological challenges, several areas were identified as needing emphasis including:

- development of appropriate standards that support applicability of organizations' datasets in GIS environment with respect to disaster response requirements,

- providing the interoperability of systems of organizations and integratability of their datasets with each other;

- increasing the technological capabilities of individual organizations and the disaster management community particularly with respect to space technologies (GIS, GPS, remote sensing, laser-scanning, LIDAR, thermal imagery, etc.), telemetry solutions (for lifeline networks, control traffic and tracking vehicles), networking, and communication facilities; and

- equipping the Emergency Operation Center with required hardware and software for data analysis and facilitating decision-making.

In terms of institutional challenges, four main areas were identified as needing emphasis:

- establishing a formal structure for GIS and spatial data affairs at group and organizational level of disaster management community;

- establishment of good relationships between organizations for data sharing by appropriate agreements that respond to needs of organizations and increase their willingness to participate;

- establishment of appropriate relationships between governmental, private and academic sectors to better utilize their capabilities; and 
- including those organizations and groups (e.g. national mapping agencies) that can provide required data for disaster response.

With respect to political challenges many factors affect participation of organizations in SDI initiative such as the current political environment of the country, ministry of Interior, and other involved organizations; interest of national mapping agencies and the historical relationship between organizations.

Finally, financial resources are required as important support for an SDI initiative in the context of economic factors.

\section{7- SDI CONCEPTUAL MODEL}

As was described earlier the five core components of SDI establish the relation between people and data through technological components (standards, policy and access network) (Fig. 1). In light of standards and policy components, producers can produce data free of duplication of efforts and share them to be accessible and applicable for users (including value-adders and end-users). Valueadders can access and enrich data for end-users, other value-adders, and their own use; and endusers can easily access and use data during their business. This is done through the access network component, which provides a physical environment for dissemination of data and access for use. The five core components of SDI and their relationships (Fig. 1) can also be regarded as a conceptual model as it describes a system in generic terms without reference to particular implementations (Davies, 2003).

With this in mind, the SDI conceptual model for disaster response was developed by expanding and clarifying each of the core components of SDI with respect to the results of the organizational assessment (Fig. 3). This SDI conceptual model is a framework that defines a clear regime for partnership of organizations in spatial data production and sharing.

\section{Fig. 3}


As Fig. 3 shows, with respect to people, three categories were identified including data providers, value-adders, and end-users (decision-makers and emergency workers) and for each category responsible organizations and their responsibilities were clarified. Two important subjects that can be described in this context are:

- Mapping agencies, particularly National Mapping Agencies that are not currently a member of the disaster management community, should be considered as a member and appropriate Standard Operation Procedures (an organizational directive that establishes a standard course of action for disaster response) should be prepared for them; and

- Training and employing volunteer bodies for data collection and analysis is essential and very beneficial as similar bodies are trained for search and rescue operations.

With respect to standards component, interoperability, metadata standards, data quality standards, and guides and specifications were identified as four important requirements. Interoperability is an important subject that needs to be emphasized in the context of standard component. Due to the time-sensitive nature of disaster response, produced data should be easily applicable in data analyzers system and also integratable with each other for real-time use. No time should be wasted by data analyzers in preparing data (such as transferring format, structuring, and referencing data) to be applicable in their systems. Therefore, there should be no heterogeneity between data providers', value-adders' and end-users' systems. In this respect, there are three sources of heterogeneity that should be brought into consideration during standardization including semantic, syntactic and schematic heterogeneities. Semantic heterogeneity is relevant to differences in definition, primitives, structure and coordinate system of data layers. Syntactic heterogeneity relates to difference in software, hardware, DBMS, and data format which is used by data provider and analyzer. Schematic heterogeneity relates to differences in data model, data coding, and topology.

Metadata, which is data about available and accessible data layers, is another important component of standards particularly for data analyzers. Metadata needs to exist so value-adders and end-users can easily identify access and utilize those data layers that best match their requirements and also 
understand the quality and reliability of datasets. Having quality standards (as another standards requirement) and producing data based on them, available data are reliable for disaster response. Guides and specifications that describe how to do a task and make the procedures standard are also essential for different tasks related to spatial data. Fig. 3, describes different subsets that are identified to be required for each of the standards components.

Policy is a very important component as it can facilitate participation of organizations in SDI initiative. These are appropriate SDI policies that can create incentive and willingness in organizations and encourage them to keep their long-term partnerships. SDI development model, institutional arrangements, policy for standards, policy for access, environment preparation, capacity building, and SDI organization were identified as seven important requirements in the context of policies.

As Fig. 3 shows, regarding the SDI development model, a product-based approach (Rajabifard, et al., 2002) was selected for SDI development because of current technological capacity of disaster management community and current status of required spatial data for disaster management with respect to availability. In order for organizations to participate in the SDI initiative, a formal mandate is essential. However, beside formal mandate, policies are required to facilitate participation of organizations in data production and sharing by removing barriers and also increasing the incentive and willingness of organizations to form partnerships. In this respect policy for access, environment preparation, capacity building and institutional arrangements are four categories of required policies that can facilitate participation of organizations in SDI initiative.

Clarifying and approving copyright and privacy laws and related concerns for spatial data are important tasks with respect to policy for access that should be considered. Clarifying data pricing and security concerns for data access are other factors in this category should also be emphasized.

Capacity building should be conducted at all three levels of the disaster management community. In this respect, economical and technological capacity building at the group and organizational levels and skill formation and increasing awareness at the individual level are important subjects that 
should be emphasized. In addition there is a need to increase the capacity of partnerships between private, academic and governmental organizations.

Cultural aspects of data sharing and providing an appropriate political environment are important tasks that should be noted in the context of environmental preparation. Institutional arrangements with respect to data custodianship, financial flow, type of partnership, and role of private and academic sectors need to be considered to facilitate partnerships by removing institutional barriers.

Having policies with respect to the practical utilization of standards by data providers and valueadders in order to meet interoperability of systems and integration of datasets with accepted quality is another important item that should be noted.

An appropriate organization for SDI is required to coordinate and follow SDI activities. A coordinating body, secretary and working groups are three tires which are recommended for this organization. The SDI coordinating body should have a peak position to be able to mandate relevant SDI approvals to other participants.

Sharing data relies on the physical relocation of data from providers and value-adders to users. Three major factors that need to be considered with respect to the accessing network are communication system, network mechanism and response time.

With respect to data, scale and resolution, content, capture (tools and mechanisms), access and analysis tools, database management, and metadata were identified as important factors and each one has been clarified (Fig. 3).

Multi-scale datasets are required for disaster management due to the need for different details of information for different kinds of decisions. Satellite and aerial imageries with different spatial, spectral (e.g. Visible, thermal and infrared) and radiometric resolutions are required for collecting different kinds of data. With respect to database, considering current capacity and cultural situation for disaster management community, designing the system based on a central database has been recommended. Having a central database, better control (with respect to participation situation and progress of database establishment) can be applied on production of datasets by organizations and hence creation of a database. Utilizing diffusion of SDI in disaster management communities and 
using a distributed database and GIS system can be a better alternative to the current recommended central database structure.

\section{8- PROTOTYPE SYSTEM FOR DISASTER MANAGEMENT BASED ON SDI}

Fig. 4, illustrates an overall picture of the community and the linkage between developed systems as well as their databases to the Emergency Operation Center (EOC) database via a network. This structure has been used as a base to design the web-based system for disaster management. Within this model, each organization has a database containing its required datasets for everyday business as well as disaster response (this database may be a central database and within the internal network of organizations). There is also a database in the EOC. The EOC Database contains base maps as well as fundamental required datasets for disaster management.

\section{Fig. 4}

Each of the involved organizations is responsible for updating one or more datasets within the EOC database before and after a disaster. Each organization can then utilize required datasets from the EOC database for their own use. This demonstrates the important concept of partnerships in producing and updating datasets, as well as the concept of sharing datasets, which allows each organization to work on a common database. As Fig. 4 shows, all of the organizations are connected to the EOC database through inter- or intranet. This is the network that organizations can use for data sharing and access their own required datasets.

The ability of all parties to have access to information that describes a current emergency situation through the development of the EOC database will enable a more coordinated response to disasters. Within this environment, the process of producing, updating, accessing and using spatial data is 
carried out based on the SDI conceptual model. This model defines standards, policies, people, access network, and data framework.

The SDI conceptual model was utilized in this project for system development and also in conducting the maneuver. For example in relation to the data component, most of the identified datasets (with respect to "content" factor) were collected and used in the system based on identified scales, resolutions and metadata information. The pilot also confirmed the need for the use of other identified factors within the SDI framework model. Data standards were developed and utilized that satisfied appropriate semantic and schematic interoperability for systems during the project. By using a centralized database, appropriate client-server architecture, a web environment, etc. the syntactic interoperability was also satisfied. Metadata standards were developed and utilized for metadata generation during data collection. Metadata was also used for searching and accessing required data during the maneuver. The data framework component was employed to develop a minimum set of guides and specifications for data production, collection and storage and the pilot project highlighted the need for other factors with respect to guides and specifications. These guides were used during the maneuver for updating the system. The need to follow data quality standards was also recognized as necessary for the reliability of the system.

In terms of the policy component of the SDI framework, different agreements, arrangements and training activities were conducted to increase the awareness of SDI so that the pilot project would be supported by the disaster management community. Some of the policy elements could be achieved by considering some specifications in the system design such as access permission control, security constrains and real-time backup. With respect to the access network, the internet was identified as the appropriate network component. In order to achieve proper response times, several map servers and data servers were also considered in the system design and appropriate band widths were recommended for communication of the system. Finally, the people component of the SDI framework involved the clarification and implementation of organisations roles and responsibilities for data production, maintenance and sharing. 
With this in mind, based on the overall picture of the disaster management community (Fig. 4), a technical and architectural design was carried out as a prototype to serve the community and was successful based on the feedback of the maneuver. Fig. 6 illustrates the technical architecture design of the prototype system. It is based on a web-based GIS for data input, access and analysis both in the EOC and within each of the involved organizations.

The system was designed based on a combined model of thick-client and thin-client architectural models (two different architectural models for developing web-based GIS; Peng and Tsou, 2003). As Fig. 6 illustrates, each of the involved organizations has their own database including their relevant datasets that are regularly updated by organizations and used for daily activities and responding to disasters. Each of the involved organizations (clients) can also access the EOC database through a web-based system.

The web-based system is based on five core components including:

- user interface for clients to access and analyze data;

- web server and application server for getting the clients' request and sending it to map server;

- map server for data analysis and queries based on clients' request;

- data server for retrieving data from a database and serving them to map server for analysis; and

- a database that includes spatial data.

Fig. 5 illustrates the core components of web-base system and their relation with each other. These core components are categorized in three tires including presentation, logic and data tiers (Fig. 6). In the presentation tier, which relates to client side, the user interface is based on a web-browser and is developed based on ActiveX controls. ActiveX control, which is developed by Microsoft and based on OLE standards, is a modular piece of software that performs tasks and communicates information to other programs and modules over the internet/intranet. Using ActiveX controls together with programming languages such as $\mathrm{C}++$ and Visual Basic a user interface for each client, based on its own GIS analysis requirements was developed. 


\section{Fig. 5}

As Fig. 5 and Fig. 6 illustrate, the involved organizations (clients) send their request to a web-server (in logic tier) via a web-browser. The web-server sends it to map servers via an application server (as translator between web server and map server). In this design, several map servers have been considered. Therefore, the system has the capability of responding to concurrent requests from different clients. For example, if the first request from one of the clients regarding getting a part of a specific dataset from EOC database is time consuming for the first map server to process, the second request from another client can be processed by other map server. The request is checked in terms of the permission of users to access the requested dataset and security considerations. Then it is sent to data servers which serve the requested dataset from the EOC database and send it to the client as Fig. 6 shows.

A replicate mechanism has been considered in the system. Based on this mechanism when a dataset is updated by a client in its own database it is replicated in the EOC database, based on defined criteria in the SDI model. Because different clients have access to the database, particular attention needs to be given to maintaining the security of the database. It is conducted using security elements that have been considered in the system. These elements control the access to databases. There is also an access record element that records the details of access to databases consisting of client IP, time of access, kind of request, etc. This is metadata about different accesses that can be referred and reviewed anytime if required.

In EOC, representatives of organizations have access to EOC database through another web-based system which can be based on a Local Area Network (LAN). Having access to EOC database, EOC is aware of the latest status of emergency situations for general planning, coordinating the response process, and controlling the situation.

\section{Fig. 6}


For the EOC and each of the clients' databases, one or two mirror databases have been suggested as a backup version. These mirror database(s) consist of the same data that exist in relevant original databases. Any change in the original in terms of producing and updating a dataset is replicated and recorded as backup in a mirror database in real time. If there is any problem with the original database, its mirror becomes active automatically. With such a design, the system is always operational and it doesn't stop due to database damage. The mirror database(s) should be located far from the originals (and each other, if more than one mirror exists) for security reasons.

According to Fig. 6 the system can be improved by employing Mobile GIS technology, in such a way that the field staff relevant to involved organizations can update the current emergency situation in their own organizations' databases using a Mobile GIS system. They can also have access to EOC database and their organizations' database for field operations.

\section{9- CONCLUSION}

This paper described a prototype web-based system as a tool and an SDI framework to facilitate disaster management by providing a better way of spatial data collection, sharing, access, usage and management.

The results of the pilot project which was conducted with collaboration of twelve organizations from the Iranian disaster management community, showed how useful such a web-based system that works based on SDI can be for effective and efficient disaster management particularly at the response phase. The effectiveness and efficiency of the system can be interpreted by different elements, however in this research reducing the response time and removing chaos by better management and coordination were considered as two evaluating factors.

It was estimated that for each of the involved organizations, such a system can help in reducing the response lasting time, at least to $1 / 3$ of current situations, by having all information available and accessible, and conducting appropriate planning prior to operational responding. Definitely, better results in terms of time saving will result if other factors such as coordinated response between 
involved parties are applied to this estimation. Time saving is an important outcome for disaster response in an emergency situation with its time-sensitive nature.

Also, the pilot project showed that using a system based on SDI, and having all information about the current situation for emergency response in the EOC database, how easily the EOC can plan for responding to disasters, control the situation, and manage the emergency to remove chaos in disaster response through better inter-organizational coordination. In addition each of the involved organizations could improve their internal coordination, having all of the information describing the latest situation of an emergency available, accessible and interoperable for use.

The main areas that this research can assist are relevant to availability, accessibility and interoperability of spatial datasets for disaster management. Using an SDI conceptual model as a framework (which has been developed based on different technical and non-technical characteristics of community) facilitates partnership efforts among different participants in which they can better resolve the current problems with spatial data.

The methodology and the model developed through this research for disaster management can also be utilized in different applications, particularly within National SDI initiatives.

\section{ACKNOWLEDGEMENT}

The authors would like to acknowledge the support of National Disaster Task Force of Iran, Tehran Emergency Management Center, K.N.Toosi University of Technology, and The University of Melbourne as well as the members of the Center of Spatial Data Infrastructures and Land Administration at the Department of Geomatics, the University of Melbourne, in the preparation of this paper and the associated research. However, the views expressed in the paper are those of the authors and do not necessarily reflect the views of the institutions that supported the preparation.

\section{REFERENCES}

Bruzewicz, A. J., 2003. Remote Sensing Imagery for Emergency Management, In: Cutter, S. L., Richardson, D.B., Wilbanks, T. J., (Eds.), Geographical Dimension of Terrorism, Toutledge, New York and London, 274pp. 
Cutter, S. L., Richardson, D. B., Wilbanks, T. J., 2003. The Geographic Dimension of Terrorism, Toutledge, New York and London,274pp.

Davies, J., 2003. Expanding Spatial Data Infrastructure model to support spatial wireless applications, PhD thesis, Department of Geomatics, The University of Melbourne, Melbourne, Australia, $210 \mathrm{pp}$.

GeoInsight, 2002. Spatial Information Network for Emergency Management in Australia, Summery of Proceedings GeoInsight Workshop, Technik Group, Australia, 18 pp.

Jain, S., McLean, C., 2003. A Framework for Modeling and Simulation for Emergency Response, Proceedings the 2003 Winter Simulation Conference, New Orleans, Louisiana, USA, 9 pp.

JICA, CEST, 2000. The Study on Seismic Microzoning of the Greater Tehran Area in the Islamic Republic of Iran, Pacific Consultants International Report, OYO Cooperation, Japan, 390 pp.

Kevany, M., 1995. A Proposed Structure for Observing Data Sharing, In: Onsrud, H. J., Rushton, G., (Eds.), Sharing Geographic Information, Rutgers, New Brunswick, New Jersey, 510pp.

McDougall, K., Rajabifard, A., Williamson, I. P., 2002. From Little Things Big Things Grow: Building the SDI from Local Government up, Proceedings Joint AURISA and Institution of Surveyors Conference, Adelaide, South Australia, 9 pp.

Nedovic-Budic, Z., Pinto, J. K., 1999. Understanding Inter-Organizational GIS Activities: A Conceptual Framework, Journal of Urban and Regional Information Systems Association, 11 (1), 53-64.

Peng Z. R., Tsou, M. H., 2003. Internet GIS: Distributed Geographic Information Services for the Internet and Wireless Networks, John Wiley \& Sons Inc, Wiley, 679pp.

Petch, J., Reeve, D., 1999. GIS Organizations and people: a socio-technical approach, Taylor \& Francis, UK, 214pp.

Rajabifard, A., Williamson, I. P., 2003. Anticipating the Cultural Aspects of Sharing for SDI Development, Proceedings Spatial Science 2003 Conference, Canberra, Australia, 9 pp.

Rajabifard, A., Feeney, M. E. F., Williamson, I. P., 2002. Future Directions for SDI Development, International Journal of Applied Earth Observation and Geoinformation, 4 (1), 11-22.

Robbins, S. P., Watters-Marsh, T., Cacioppe, R., Millett, B., 1994. Organizational Behavior: concept, controversies and applications, Prentice Hall, Australia and New Zealand, New York, London, Tronto, Sydney, Tokyo, Singapore, 753pp

SNDR, 2002. A National Hazards Information Strategy: Reducing Disaster Losses through Better Information, National Science and Technology Council, Committee on the Environment and Natural Resources, Subcommittee on Natural Disaster Reduction (SNDR), Washington, DC, April 2002, $44 \mathrm{pp}$.

\section{INTERNET REFERENCES}

Amdahl, G., 2002. Disaster Response: GIS for Public Safety, ESRI, Redlands California. http://www.esri.com/news/arcnews/winter0102articles/gis-homeland.html - visited on October 2002.

Donohue, K., 2002. Using GIS for All-hazard Emergency Management, http://www.edc.uri.edu/nrs/classes/nr5409/509-2002/donahue.pdf - visited on February 2004.

IRSC, 2004. Iranian Red Crescent Operations: A Summery of Activities and Achievements in Bam Earthquake, Report of Iranian Red Crescent Society to United Nations about relief and rescue operations in Bam, March 2004, http://www.irrcs.org - visited on February 2004. 
ISDR, 2003. Basic Terms of Disaster Risk Reduction, International Strategy for Disaster Reduction, United Nations, http://www.adrc.or.jp/publications/terminology/top.htm - visited on Jan 2004

\section{FIGURE CAPTIONS}

Fig. 1: SDI Components

Fig. 2: Basic Organizational Behavior Model and Selected Variables at Each Level for Organizational Assessment

Fig. 3: Schematic Presentation of SDI Conceptual Model for Disaster Response

Fig. 4: Overall Picture of a Web-Based System to Facilitate Disaster Management Using an SDI Environment

Fig. 5: Core Components of Web-Based System and Their Relations

Fig. 6: Technical Architecture of Prototype Web-Based System 


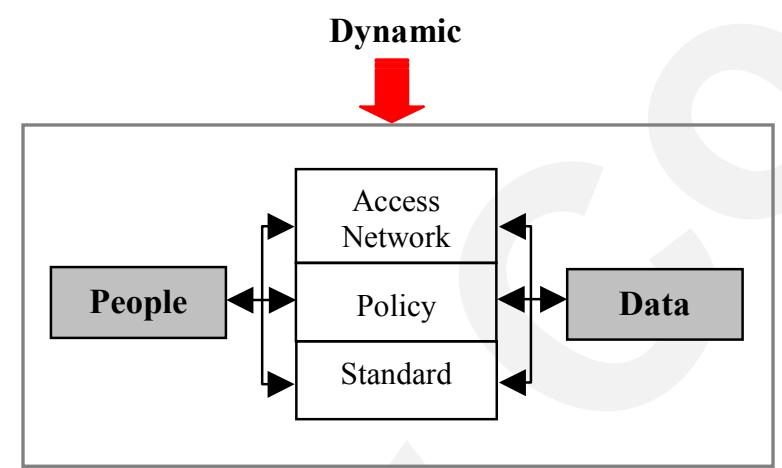

Figure 1 


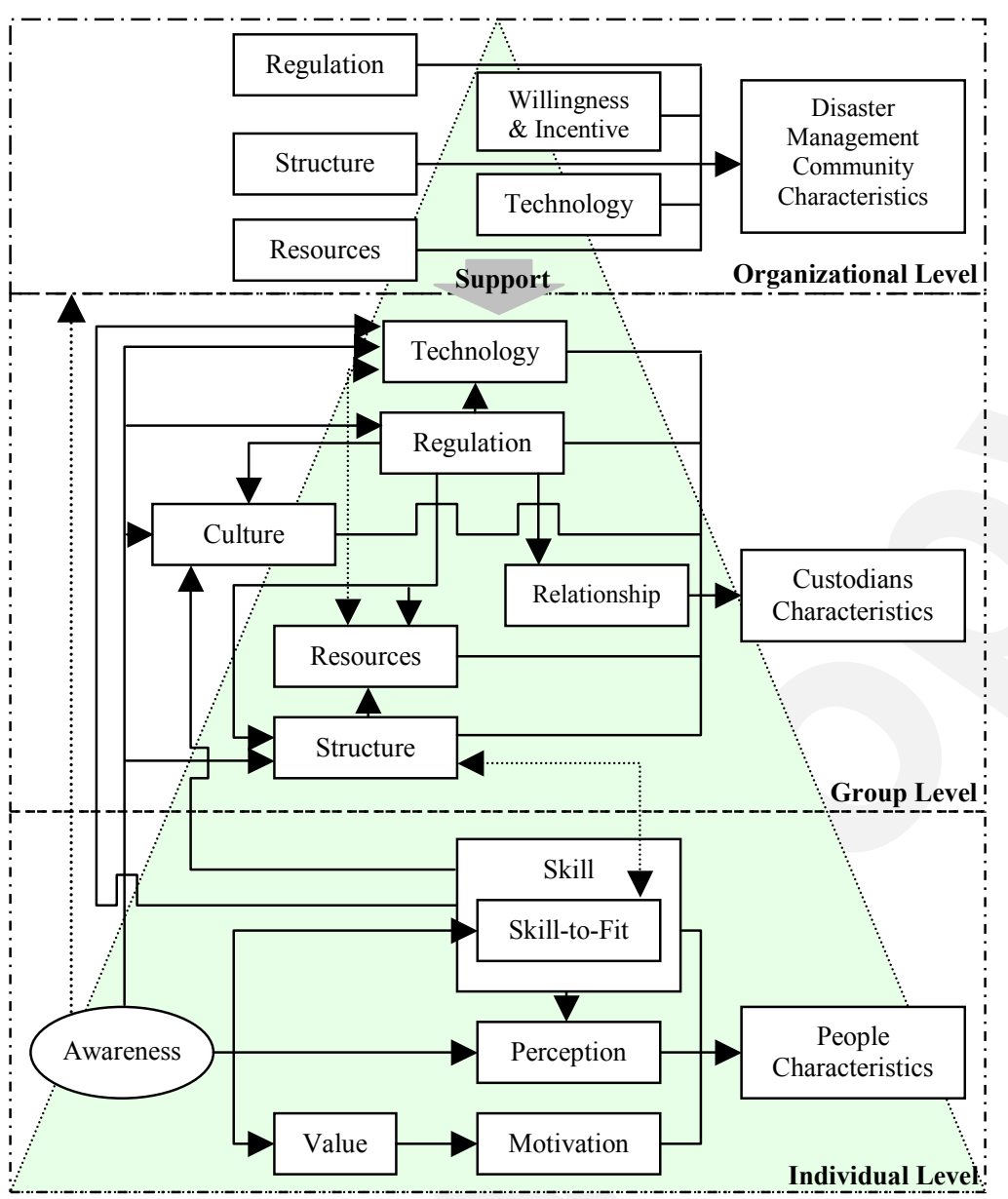

Figure 2 


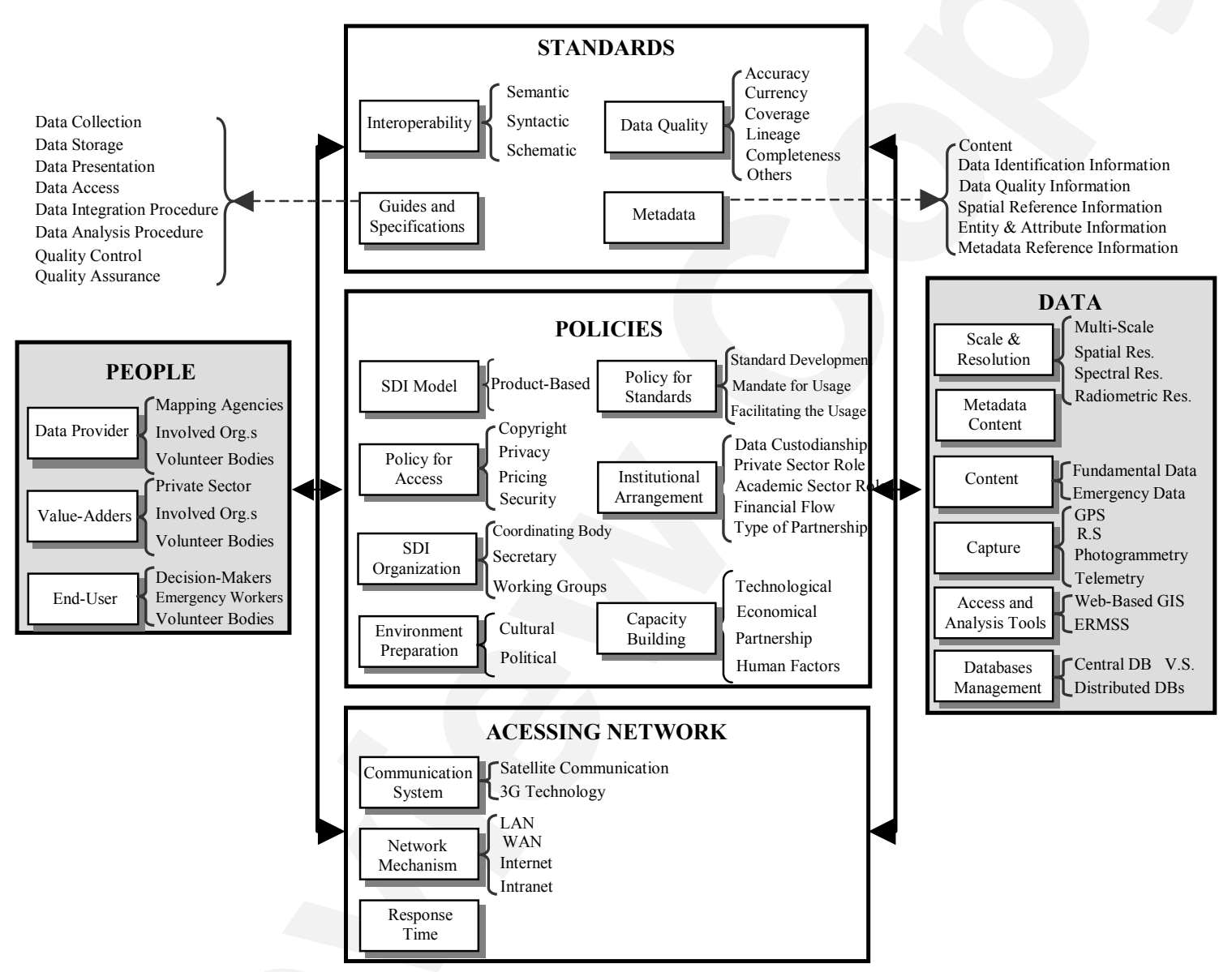

Fig. 3 


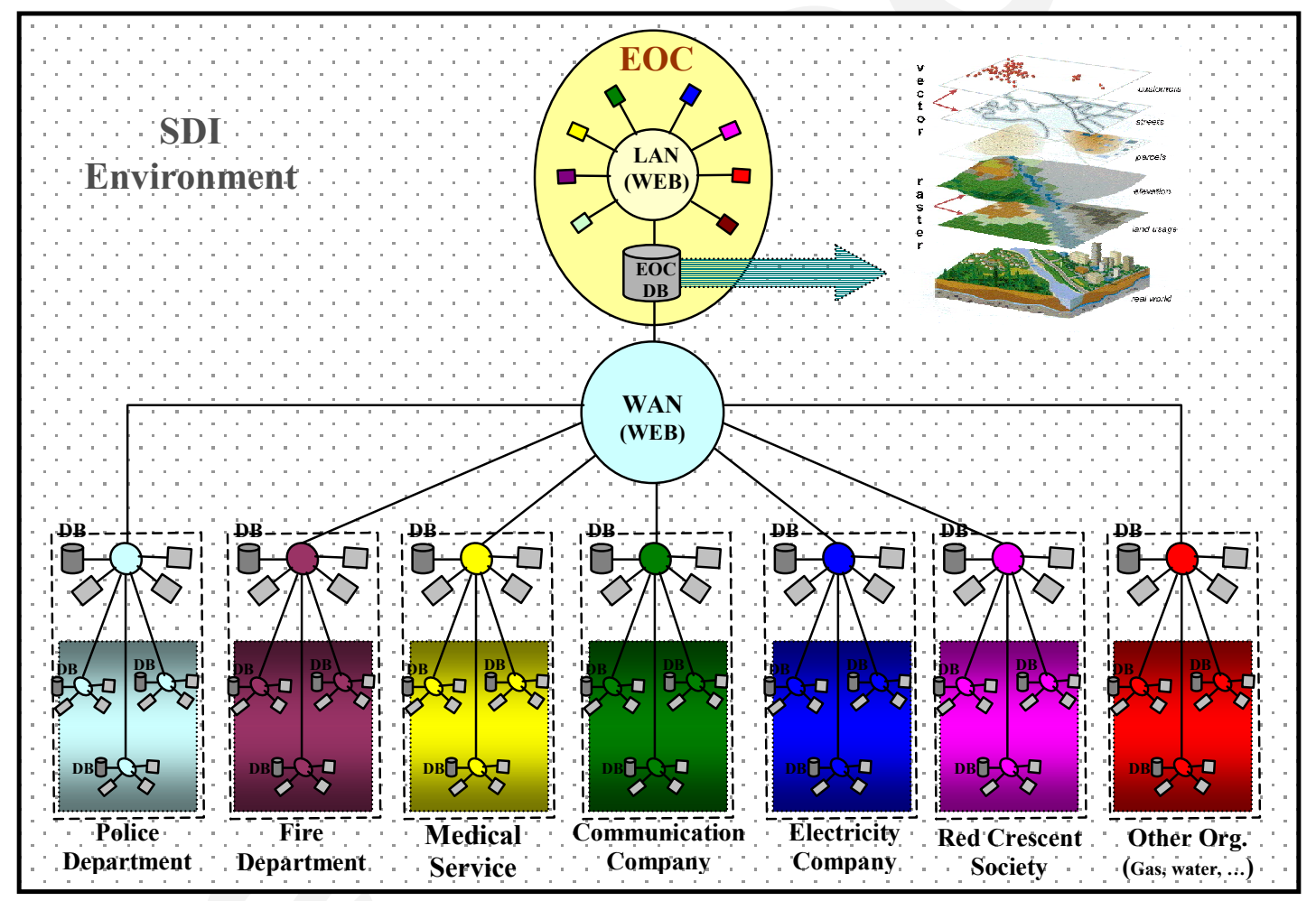

Fig. 4 


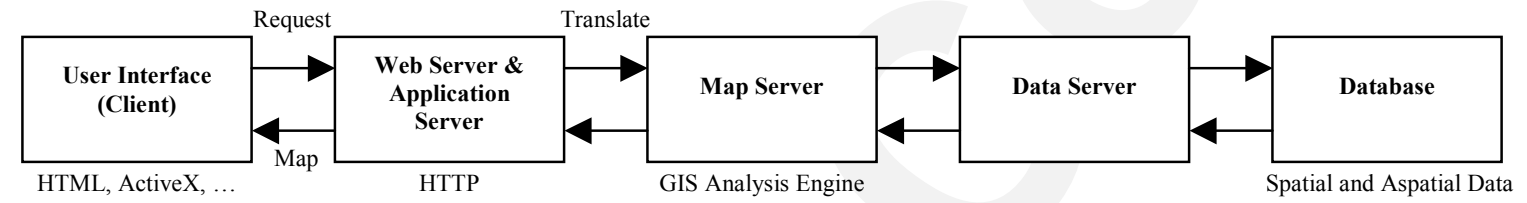

Fig. 5 


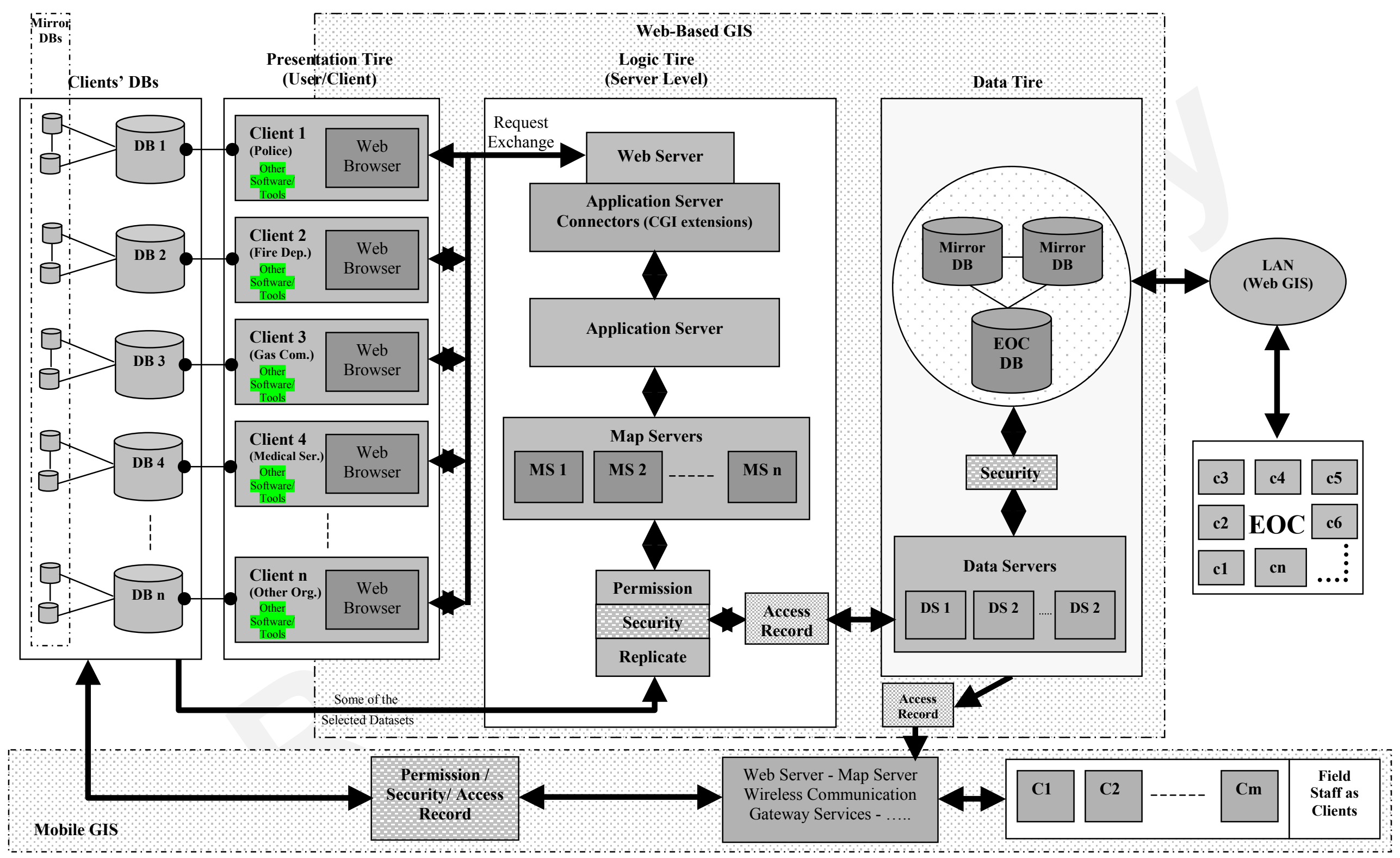




\section{University Library}

\section{- M M I N E R VA A gateway to Melbourne's research publications}

Minerva Access is the Institutional Repository of The University of Melbourne

Author/s:

Mansourian, A;Rajabifard, A;Zoej, MJV;Williamson, I

Title:

Using SDI and web-based system to facilitate disaster management

Date:

2006-04-01

Citation:

Mansourian, A., Rajabifard, A., Zoej, M. J. V. \& Williamson, I. (2006). Using SDI and webbased system to facilitate disaster management. COMPUTERS \& GEOSCIENCES, 32 (3), pp.303-315. https://doi.org/10.1016/j.cageo.2005.06.017.

Publication Status:

Published

Persistent Link:

http://hdl.handle.net/11343/26707 